\title{
The demand for air quality: evidence from the housing market in Bogotá, Colombia
}

\author{
Fernando Carriazo $^{1 *}$ and John Alexander Gomez-Mahecha ${ }^{2}$ \\ ${ }^{1}$ Universidad del Rosario, Calle 12C No. 6-25 - Bogotá DC, Colombia and \\ ${ }^{2}$ Universidad de Los Andes, Bogotá, Colombia \\ *Corresponding author. Email: fernando.carriazo@urosario.edu.co
}

(Submitted 30 June 2016; revised 1 January 2018; accepted 7 January 2018)

\begin{abstract}
Identifying a demand function for air quality is a key input to calculate welfare measurements of pollution abatement policies. We defined intra-urban housing submarkets to apply a Second Stage hedonic pricing model that allowed us to identify an inverse demand function for PM10 reductions in Bogotá. The monthly benefits of compliance with the U.S. Environmental Protection Agency standard $\left(50 \mu \mathrm{g} / \mathrm{m}^{3}\right.$ - annual average), and the far more stringent World Health Organization standard $\left(20 \mu \mathrm{g} / \mathrm{m}^{3}\right.$ - annual average $)$ are valued at US\$12.16 and US\$189.64 per household, respectively. These values, in turn, represent about 1.35 per cent and 21.04 per cent of the average household income. The hedonic model applied hereby shows that intra-urban housing submarkets are suitable for the identification of a demand function to be used by policy makers interested in evaluating non-marginal benefits (costs) from air quality improvements (deterioration).
\end{abstract}

Keywords: Air pollution; Bogotá; EPA; hedonic models; housing markets

JEL Classification: Q51; Q53; R31

\section{Introduction}

This study estimates welfare benefits related to air quality improvements that are indirectly revealed through property values in Bogotá. Most stations from Bogotás monitoring network recorded admissible levels for carbon monoxide (CO), sulfur (SO2) and nitrogen dioxides (NO2), and ozone (O3). However, as judged by the local pollutants standards, readings for PM10 exceeded the annual local air quality standard of $50 \mu \mathrm{g}$ per cubic meter, especially in Puente Aranda, the city's main industrial area (Gaitán et al., 2007).

Most studies examining individual preferences for clean air are based on the hedonic model framework (Rosen, 1974) using the so-called First Stage (FS) estimation, where residential prices are a function of structural characteristics, and neighborhood and environmental amenities surrounding the housing unit location. Previous hedonic 
applications in Bogotá have found a consistent negative correlation between air quality and housing prices using FS models (Morales and Arias Arbeláez, 2005; Carriazo et al., 2013). Although these studies contribute to understanding how air quality improvements capitalize into property values, and they are informative as exploratory tools to determine implicit prices for marginal pollution reductions, we argue that they are not necessarily suitable to determine welfare effects from non-marginal changes in air quality. Even though FS hedonic applications are useful for recovering the implicit prices of non-marketable characteristics, they are of limited applicability to calculate welfare benefits for non-marginal changes because the FS only recovers a point of the demand curve of each agent in the market. The Second Stage (SS) hedonic model solves this problem, in part, by identifying a demand function (willingness-to-pay function) that allows to value non-marginal changes in air quality monetarily. Our work focuses on the identification of the demand for reductions of Particulate Matter (PM10).

Calculating the welfare effects from non-marginal changes is important as the local environmental agency has made efforts to curb pollution levels, mostly based on command and control policies such as the programmed reduction of sulfur in diesel fuels. However, very little is known on the potential welfare effects of air quality improvements. Neither welfare nor cost benefit analysis have been done to quantify such potential welfare effects in Bogotá.

Our study contributes to welfare analysis of air quality improvements in Bogotá by identifying a demand function for PM10 reductions - our measure of air quality - using an SS hedonic application. This study also intends to enrich the discussion on the empirical application of the hedonic model. We suggest that the methodology used hereby can be applied to several cases so that more accurate estimations of air quality effects could be achieved. The analysis of welfare effects related to changes in ambient quality based on a demand function identified from an SS hedonic model could be an important and flexible tool for environmental policy decision makers: first, by identifying a demand function for air quality, consumer surplus measures due to the compliance with emission standards can be calculated; and, second, social benefits can be incorporated into cost/benefit analyses of environmental investments and pollution control policies.

SS estimations of the hedonic model are scarce in the non-market valuation literature due in part to challenging data requirements and estimation complexities regarding two specification issues: identification and endogeneity. Although implicit marginal prices have been estimated in emerging economies like Colombia or Chile, we did not find studies implementing SS hedonic models to value non-marginal benefits from air quality improvements in the context of emergent economies. We intend to fill this gap in the literature. To our knowledge, this study is the first application of the hedonic model in Bogotá using an SS model proposing a market segmentation strategy and an estimation of an instrumental variable (IV) to address identification and endogeneity issues. For identification, we propose separate real estate markets within an urban area based on three types of properties: apartments, houses, and houses that are condominiums (hereafter condominiums). This type of segmentation is also rare in the hedonic literature since most hedonic applications valuing urban amenities do not consider the possibility of several markets within a single urban area.

Our final analysis includes counterfactual scenarios to calculate potential welfare effects derived from pollution control policies aimed to comply with the U.S. Environmental Protection Agency (EPA) standard, and the World Health Organization (WHO) more stringent standard. Estimation of total willingness to pay (TWTP) for particulate matter reductions suggest an average per household monthly benefit of US $\$ 12.16$ 
for compliance with the EPA standard, and US\$189.64 for compliance with the WHO standard.

The remainder of this paper is organized as follows: section 2 discusses first and second stage hedonic models applied to air quality. Section 3 presents the econometric model to identify the air quality demand and the proposed welfare measures. Section 4 describes the study area and the data used for estimations. Section 5 presents empirical results and section 6 includes a final discussion.

\section{Hedonic pricing models and air quality}

This research uses Rosen's (1974) hedonic pricing theoretical framework to identify the demand for air quality in Bogotá. In the so-called First Stage (FS) of the model, the well-known Hedonic Price Function (HPF) is estimated. Rosen showed that at the optimum, the marginal bid, also known as the implicit price of the characteristic, equals the marginal rate of substitution between the characteristic and a Hicksian bundle of goods. In equilibrium, the implicit price of the housing characteristic also equals the supplier's marginal cost. The HPF gives the locus of equilibrium points where theoretically a consumer and a supplier of a dwelling are willing to pay and accept, respectively, the same amount of money for each of the housing characteristics. The economic literature has thoroughly addressed the theoretical hedonic equilibrium condition describing First Stage implicit prices and the so-called Second Stage (SS) demand relationship between implicit prices and the level of a characteristic (Rosen, 1974; Freeman, 1979; Taylor, 2003; Palmquist, 2005).

\subsection{First stage studies}

Most empirical hedonic applications exploring the relationship between property values and environmental quality to estimate marginal implicit prices for air quality are based on FS hedonic models, where the HPF is empirically estimated by regressing the prices of housing as a function of its characteristics, including the environmental quality of the surrounding area.

The earliest application that examined the relationship between property values and air pollution, to our knowledge, is Ridker and Henning (1967). This early classic work has inspired a myriad of studies dealing with methodological aspects of empirical estimations to identify marginal implicit prices for air quality. Extensive reviews of early works reporting marginal implicit prices for air pollution are found in Smith and Huang (1993, 1995), Boyle and Kiel (2001), and Freeman (2003). More recent research has focused on the methodological aspects of the HPF estimation while gathering evidence of the implicit prices from air quality. This group includes the following approaches: (1) the study of spatial structures in the HPF estimation (Kim et al., 2003; Neill et al., 2007; Anselin and Lozano-Gracia, 2008); (2) the endogeneity of the pollution variable (Chay and Greenstone, 2005; Bayer et al., 2006; Anselin and Lozano-Gracia, 2008); (3) air quality measurements (Anselin and Le Gallo, 2006; Mínguez et al., 2013); and (4) the mitigation of omitted variables bias in the HPF estimations (Vásquez et al., 2011; Carriazo et al., 2013).

\subsection{Second stage studies}

Second Stage (SS) hedonic models are less common in the empirical studies that use the hedonic framework to value benefits from environmental quality improvements. 
Kuminoff et al. (2010) claim that Rosen's (1974) SS entails methodological challenges due to problems of identification and endogeneity in estimations, in addition to the significantly high demand for data. These complications explain, in part, the very few empirical applications of this stage of the model. Historically, to our knowledge, with the exception of Harrison and Rubinfeld (1978), who identified a demand for NOx in Boston, most of the hedonic studies conducted, at least until 1993, estimated only the relationship between housing prices and air quality, but did not complete Rosen's SS (Smith and Huang, 1993). This stage involves the estimation of the demand for welldifferentiated characteristics using hedonic prices (Taylor, 2003). The SS of the hedonic price model captures the demand for a given characteristic by combining implicit prices derived from the First Stage with socio-economic data that could reflect consumers' housing preferences. Particularly with these estimations, welfare measures could be derived by defining the utility parameters for a given utility function, or by using the demand function to estimate a lower bound of total benefits to changes in a specific attribute.

Subsequent to Smith and Huang's (1993) thorough review of hedonic applications for air quality, we found that the SS approach has been very limited in the literature. In fact, most examples of this approach are not very recent; some of these focused on structural characteristics such as number of available bathrooms (Palmquist, 1984), and others on the physical condition of a neighborhood (Bartik, 1987). Very few studies have explored the SS estimation for environmental amenities; Boyle et al. (1999) use various model structures for their estimation of an inverse demand of water clarity for properties near a lake in Maine.

In practice, identification methods of the SS consist of the estimation of the HPF for several markets and the construction of a pooled database of implicit prices from the FS regressions to estimate an inverse demand function (Palmquist, 1984; Bartik, 1987). Definition of a housing submarket is not trivial, and in many cases, its implication for hedonic estimations has been ignored. Using a single metropolitan market to identify parameters of the HPF when in reality there are several submarkets may lead to erroneous parameter estimates (Goodman and Thibodeau, 2003; Palmquist, 2005).

After Smith and Huang (1993), we identified just two studies applying the SS approach for estimating welfare benefits from air quality improvements (Chattopadhyay, 1999; Zabel and Kiel, 2000). The studies used two different methods for solving the identification issue. In the first approach, the demand is identified essentially by regressing the marginal implicit price from the FS hedonic function as a function of the marginal rate of substitution, the theoretical equilibrium condition that results from a predefined functional form of the HPF and of the utility function (Chattopadhyay, 1999). The second approach (Zabel and Kiel, 2000) identifies the demand function by using information from different markets, as suggested by Taylor (2003).

Traditionally, multiple markets in SS hedonic applications are defined by temporal variation or spatial variation. Implicitly, this approach assumes that consumers with similar socio-economic characteristics have the same preferences, independent of the housing submarket they are a part of (Palmquist, 2005). Taylor (2003) reports that the number of housing markets that have been used for identification vary from two to thirteen, highlighting that although there is no rule of thumb for the number of submarkets to be used in estimations, it is important that the hedonic function vary among markets.

Chattopadhyay (1999) uses the theoretical equilibrium condition to estimate welfare changes from air quality improvements in the Chicago housing market. The author uses PM10 and sulfur dioxide as measures for air quality. The estimates of marginal 
willingness to pay for PM10 ranges from US\$268 to US\$363 in 1989-1990 dollars. Nonmarginal benefits from a 25 per cent reduction of PM10 levels ranged from US $\$ 2,037$ to US $\$ 3,350$. In the case of sulfur pollution, the mean marginal willingness to pay ranged from US $\$ 878$ to US\$1036, while non-marginal benefits from a 25 per cent reduction of sulfur pollution ranged from US\$1353 to US\$1925 in 1989-1990 dollars.

Zabel and Kiel (2000) estimate the demand for air quality using the American Housing Survey of Chicago, Denver, Philadelphia, and Washington, D.C. The SS estimation assumes each city is a submarket, exploiting temporal variation of housing prices and pollution levels. Results from the demand for air quality are used to estimate nonmarginal benefits from increasing air quality to meet the U.S. Ambient Air Quality Standards. They found benefits ranging from US\$171 million in Denver to US\$953 million in Philadelphia.

In the next section, we describe the econometric model and empirical strategy we used to identify the demand for PM10 reductions, based on the Second Stage (SS) hedonic model.

\section{Econometric model}

The econometric model to measure the willingness to pay for air quality improvements is based on the theoretical assumption where households consider structural characteristics, neighboring attributes, and pollution levels in their housing choices, as the economic literature extensively details (Rosen, 1974; Freeman, 1979; Taylor, 2003; Palmquist, 2005). The theoretical model assumes that households maximize their utility $U(Z, X)$ subject to the budget constraint $X+P(Z)=Y$, where $Z$ represents a vector of housing characteristics $\left(z_{1}, z_{2}, \ldots, z_{n}\right)$, including structural characteristics, neighborhood attributes, and air pollution concentration; $X$ represents a Hicksian bundle of other goods; $Y$ represents household monetary income; and $P(Z)$ denotes the price of a house with attributes $Z$, that is the housing HPF. A more detailed explanation of the theoretical model is available in the online appendix.

In the optimum state, a household would choose a level of attribute so that $(\partial P / \partial Z)=$ $(\partial U / \partial Z / \partial U / \partial X)$. In this framework, the optimal condition states that a household's willingness to pay for a marginal change in air pollution equals the marginal rate of substitution between air quality and other goods. To recover this willingness to pay for the marginal change in air pollution, we can calculate the derivative of the hedonic price equation with respect to air pollution in the FS. When this derivative is calculated separately for each household, it is an estimate of the marginal willingness to pay for an improvement in air quality. In our case, where a multiple market approach is used for solving the identification issue, the hedonic price equation $P(Z)$ should take the general form:

$$
\ln \left(P_{i j}\right)=\beta_{0 j}+\beta_{Z j}^{\prime} \cdot Z_{i j}+\beta_{K j}^{\prime} \cdot A_{i j}+\beta_{j} \mathrm{PM} 10_{i j}+u_{i j} \forall_{j} \in J
$$

where, $P$ is the price of housing $i(i \in\{1,2, \ldots, n\})$ belonging to submarket $J(J=$ $\{1, \ldots, m\}), Z_{i j}$ is a vector of $Z_{j}$ structural characteristics of housing for each dwelling $i$ in submarket $j, A_{i j}$ is the vector of $K_{j}$ neighborhood attributes for house $i$ in submarket $j$, and a semi-log (log-lin) relation is assumed to capture non-linearities in prices. Concentration of particulate matter less than $10 \mu \mathrm{m}$ (PM10), measured in $\mu \mathrm{g} / \mathrm{m}^{3}$, is the variable we use as a measure for environmental quality, our variable of interest in this research. $\beta_{0}, \beta_{Z}^{\prime}, \beta_{K}^{\prime}, \beta_{j}$ are parameters to be estimated for each market $j$ and $u_{i j}$ is a random error $\sim N\left(0, \sigma_{j}^{2}\right)$. This functional form also has been used widely in FS hedonic 
price applications. For the log-lin functional form, the marginal willingness to pay for air quality in each market $j$ and for each house $i$ is given by:

$$
\frac{\partial P_{i j}}{\partial \mathrm{PM} 10_{i j}} \approx-\hat{\beta}_{j} P_{i j} \approx W\left(\mathrm{PM} 10_{i j}\right)
$$

where $W\left(\mathrm{P} M 10_{i j}\right)$ denotes the marginal willingness to pay of agent $i$ in submarket $j$ for air quality or its implicit price.

As suggested by the hedonic pricing model literature, the estimation of the HPF in the FS is particularly affected by the omitted variable bias. This bias, in turn, should subsequently affect the estimation of the SS. The proposed estimation strategy takes into account the omitted variable issue by including neighborhood characteristics, fixed effects, and further assuming an asymmetric structure of the random error through the estimation of a Frontier Model. Neighborhood quality is usually misrepresented in the data used for FS estimations, given the inherent difficulty in obtaining relevant data for it. Because this quality is important for determining the price of each dwelling, not having this information is one of the principal sources of omitted variables. We mitigated this bias through the geocoding of dwellings up to the census block level that allowed us to merge them with geocoded information of the neighborhood quality score from the local cadastral institution (Unidad Administrativa Especial de Catastro Distrital CATASTRO). Geocoding also allowed us to have information on distances to other local amenities. In addition, we also followed common strategies for mitigating omitted variables bias including spatial fixed effects based on Bogotá's administrative sub regions or localities. ${ }^{1}$ Our specified model also includes air quality measures different from the one of interest (PM10) and the assumption of an asymmetric random error that may capture unobserved dwelling quality whose variance function depends on pollution levels, as discussed in Carriazo et al. (2013).

The FS model is thus estimated by specifying a hedonic frontier model (HFM), using the maximum likelihood method as follows:

$$
\ln \left(P_{i s j}\right)=\beta_{0 j}+\beta_{Z j}^{\prime} \cdot Z_{i s j}+\beta_{K j}^{\prime} \cdot A_{i s j}+\beta_{Q j}^{\prime} \cdot Q_{i s j}+\gamma_{s j}+\beta_{j} P M 10_{i s j}+u_{i s j}+v_{i s j} \forall_{j} \in J
$$

where $Q_{i s j}=\left[q_{1 i s j}, \ldots, q_{Q_{j} j}\right]$ is a vector of $Q_{j}$ air quality variables for the submarket $j$, varying among Bogota's administrative divisions $(s)$, and $\gamma_{s j}$ are the spatial fixed effects, represented by dummy variables for each administrative division. $Z_{i s j}$ is a vector of structural characteristics, $\left(A_{i s j}\right)$ is one of neighborhood attributes, and PM10 is Particulate Matter concentrations, our variable of interest, with subscripts defined as before. Finally, the error term has two components: the $v_{i s j}$ is the usual symmetric and mean-zero random error term for each submarket $j$, and $u_{i s j}$ in this model is an asymmetric error. This

\footnotetext{
${ }^{1}$ Bluntly, in order of importance and size, four spatial hierarchies of political-administrative divisions are observed in Bogotaì: (1) administrative subregions or localities, (2) Unities of Zonal Planning (UPZ), (3) neighborhood (barrios) and (4) census block (manzanas). For each house in the available database we have identified the census block and the administrative subregion where it is located. In the data described ahead, we have an average of seven dwellings (6.83) per census block and a mean of 89 blocks per administrative division. The census block is the smallest geographical unit at which we could identify the position of each household. The average pollution levels at this spatial unit were used to assign the contamination levels for each of the dwellings. For this reason we could not use fixed effects at the census block level; otherwise we would not have variance in the pollution variable.
} 
error component captures unobserved housing quality that tends to be asymmetric and correlated with environmental quality. Following Carriazo et al. (2013), we specified the variance function of the asymmetric component as:

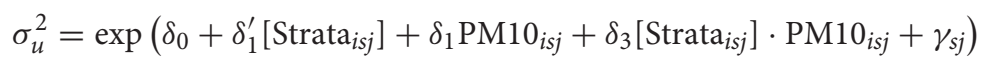

The variance of the asymmetric error term depends on air quality, the dwelling strata and their interactions, where Strata captures general information about the socio-economic characteristics of the dwelling and its occupants. ${ }^{2}$ By including spatial fixed effects (based also on Bogotá's administrative divisions) in the asymmetric error specification, we will also be relaxing the assumption of spatially independent observations. Carriazo et al. (2013) showed that the Hedonic Frontier Specification is suitable to mitigate Omitted Variable Bias in the presence of unmeasured quality attributes of residential properties that are correlated with environmental quality. In their estimations, they found a price elasticity for air quality 25 per cent higher in the OLS specification than in the HFM. Usually, HFM estimates are obtained from a single sample and estimated on a case-bycase basis.

The FS hedonic model thus encompasses the estimation of equation (3) and the calculation of (2) for each housing market. For estimations, we assumed that the city is not a unique housing market but rather composed of three submarkets. We propose a housing market segmentation in Bogotá based essentially on the type of properties, namely $J=\{$ Houses, Condominiums, Apartments $\}$.

Market segmentation is an important feature of our model because it allows for variation in price schedules necessary for the identification of the demand function for air quality. Most research uses an urban area as a single market without discussing its consequences (e.g., Palmquist, 1984; Bartik, 1987; Boyle et al., 1999; Chattopadhyay, 1999; Zabel and Kiel, 2000). It is also a common practice to merge data from different time periods. Moreover, some authors have considered that a market can be defined by year; therefore, the same city in $\times$ years is considered as $\times$ different markets (e.g., Zabel and Kiel, 2000). In the absence of data for different time periods, we propose a market segmentation based on the type of properties discussed above, thus separating markets by a structural attribute rather than by time. Intuitively, this segmentation makes sense because each type of property offers different amenities for different consumers, so they should have different HPFs, which is enough for SS derivation.

Two concerns about this identification strategy may arise: (1) why should each of the defined submarkets have a different HPF? and (2) are only three submarkets enough for identifying the demand function?

Households living in each type of dwelling, arguably, reveal preferences for different housing attributes: condominiums are likely to have better security conditions than detached houses, or a better quality of surrounding green areas, whereas apartments may provide nicer views and higher security than detached homes and condominiums. Similarly, each dwelling offers attributes that others do not (e.g., elevators, communal services, land rights). Furthermore, housing consumers may relate differently to

\footnotetext{
${ }^{2}$ Strata is a categorical variable taking values from 1 to 6 . Each value classifies population in six different groups with 'similar' socioeconomic characteristics. Bluntly, this classification is used to determine ranges of income for the population. Strata 1 and 2 group lower income households, 3 and 4 middle income, and 5 and 6 upper income households. The basic unit of stratification is the census block, so all houses at the same block belong to the same stratum. Stratification is also used as a reference to determine the amount that is charged for public utilities such as water, electricity and telephone.
} 
the same attribute (e.g., a high number of floors in buildings can be a positive desirable attribute for apartments but not necessarily for houses). Additionally, when the same attribute is available for the three types of dwellings, the housing price effect of the attribute may change because of variations in the supply of it. For example, increasing private green areas could have a different price effect on houses compared to apartments because initial amounts of green spaces associated with the dwellings may not be the same. The supply of housing may also differ for each type of dwelling. One may expect that the supply of detached houses or condominiums decreases within an urban area as densification processes of cities trigger land prices. Finally, family composition may be related to a particular housing preference. Families with children may prefer to live in houses rather than in apartments due to likely gains in space and amenities, such as a backyard.

Although the previous discussion suggests that from a theoretical point of view it is plausible to define submarkets based on the types of dwellings, we admit that our data is not the most suitable to offer detailed empirical proof in this regard. Nonetheless, we reviewed some reports on market data that support the proposed segmentation: several local and national institutions collect information on the construction sector showing differences in indicators related to houses and apartments, as well as to uni-familiar and multi-familiar constructions. Their results show how basic indicators such as the properties price index (SIC, 2012; DANE, 2017) and the production cost index (DANE, 2016) vary substantially among different types of dwellings. ${ }^{3}$ This is an expected behavior supporting our assumption of market segmentation.

The second common concern about the proposed design is the use of only three submarkets for the identification of the SS empirical estimation. As mentioned before, Taylor (2003) argues that the number of markets in previous estimations has varied from two to thirteen. The author claims that, 'There is no established correct minimum number of individual markets required. Of course, what must be established is that the Hedonic Price function do vary across markets' (Taylor, 2003: 374)

Cheshire and Sheppard (1998) and Bartik (1987) used information from just two markets to identify the demands of several dwelling attributes in two cities in England and the United States, respectively. Rosen (1974) provides another reason why three submarkets could be enough for identification, by arguing that nonlinearities can be also a source of variation. Nonlinearities in the HPF will allow the coexistence of different implicit prices for the amenity of interest in the same market, and actually there are a few reasons that could justify a linear form for the FS estimation. Palmquist (2005) argues that a linear $\mathrm{HPF}$ would be relevant only if it were possible to move characteristics between dwellings easily, indicating that arbitrage would force a linear price schedule. Because this is not the case, the HPF need not be linear.

Our work focuses on the estimation of benefits from non-marginal changes of PM10, whose reductions are a proxy of our air quality measure. The FS hedonic model estimation is not suitable to determine each household's willingness to pay for non-marginal improvements of air quality. To do so, we need to estimate the relationship between air pollution levels, PM10, and its marginal implicit price, $W$ (PM10), in a SS. Thus, the

\footnotetext{
${ }^{3}$ Reports from the National Statistics Office (DANE) indicate that for the first quarter of 2017 the property prices index varied by $1.81 \%$. However, this variation was different for houses and apartments. The reported variation for apartments was $1.78 \%$, while the variation for houses was $2.34 \%$. The annual cost of materials for apartments varies by $1.43 \%$, while this variation for houses was $0.95 \%$.
} 
willingness-to-pay equation is an uncompensated inverse demand function for air quality estimated by regressing households' marginal implicit prices in (2) on air pollution levels, households' socioeconomic characteristics, and other demand shifters, such as household income. Thus, our specification for the willingness-to-pay function for air quality (inverse demand) is given by:

$$
W\left(\mathrm{PM}_{i j}\right)=\beta_{0}+\beta_{1} \mathrm{PM} 10_{i j}+\beta_{2} Y_{i j}+\beta_{\mathrm{S}}^{\prime} \mathrm{S}_{i j}+\varepsilon_{i j}
$$

The left-hand side of (5) is the implicit price for air quality from the FS HPF calculated in (2); PM10 is our proxy for air quality; $Y$ is household income; and $S$ is a vector of households' socioeconomic characteristics in each defined submarket. Sub-index $i \in\{1 \ldots n\}$ refers to household and $j \in\{1,2,3\}$ refers to the housing submarket. OLS estimation of (5) may be inconsistent due to the problem of endogeneity associated with the simultaneous determination of the marginal implicit price and the level of air quality. Thus, the level of pollution is correlated with the error term of the OLS estimation of the SS inverse demand equation (5). We propose a Two Stage Least Squares (2SLS) method to correct for this endogeneity and instrument PM10, using precipitation, wind speed, and PM10 spatial lags as instruments. Haussmann tests for suitability of instruments are presented in section 5 .

\section{Study area and data}

\subsection{Study area}

Information from the rental housing market was used to estimate a demand for air quality in Bogotá D.C. Bogotá's air quality, our variable of interest, has been one of the main public concerns and one of the most important issues on the city's environmental agenda. Particularly, high levels of PM10 recorded over several years have made particulate matter the main contaminant and the focus of the most important air quality measures. PM10 exceeds the air quality city standards (annual standard for the city: $55 \mu \mathrm{g} / \mathrm{m}^{3}$ ), particularly in Bogotá's main industrial area (the locality of Puente Aranda). This result agrees with the SDA's (2011) assessment that relates this phenomenon to the use of fossil fuels, especially diesel with its high sulfur content. Air quality varies spatially within the urban area. Figure 1 reveals the important differences of PM10 concentrations within the city.

Readings from monitoring stations located in the south and southwestern areas were consistently higher than those from the north in recent years. In 2011, seven of the 11 reported stations present levels over other national and EPA standards, and all of them report levels higher than the suggested World Health Organization limits. Important reductions of PM10 have occurred, since there was a gradual decline of the annual mean concentration from 65 to $52 \mu \mathrm{g} / \mathrm{m}^{3}$ in the 2002-2014 period. However, the city's average is still above the permissible limits.

\subsection{Data}

The data used for estimations include 11643 housing units obtained from Bogotá's Multiple Purpose Survey of 2011 (Encuesta Multipropósito de Bogotá - EMB, 2011), which randomly sampled the households' population. The National Statistics Department (Departamento Administrativo Nacional de Estadistica - DANE) and the District Planning Office (Secretaría Distrital de Planeación - SDP) jointly developed this survey 


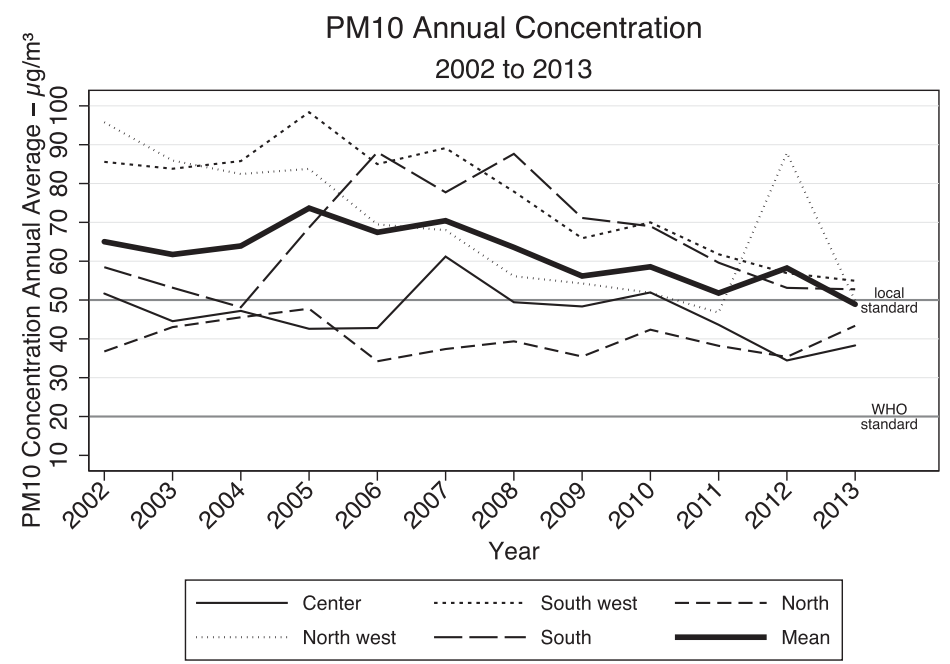

Figure 1. PM10 Annual Concentration

to capture the socio-economic conditions of households in the city, and to learn about household decisions and lifestyles.

EMB also captures information on dwellings' structural configurations as well as other relevant neighborhood characteristics. Apartments are the most common type of dwelling, representing almost 62.4 per cent of the market, followed by houses $(31.6$ per cent), and condominiums (5.9 per cent). ${ }^{4}$ On average, each house has 3.63 rooms and 1.59 bathrooms, in an area of almost $135 \mathrm{~m}^{2} .41 .09$ per cent of the dwellings have a garage, 40.84 per cent have a garden, and 29.49 per cent have easy access to green areas. Regarding tenure, most households are owners; only 38.65 per cent are renters. The average rent is COP\$464,159.5 per month (US\$251.3), which represents 35.72 per cent of the Head of Household's ( $\mathrm{HH}$ ) income and 22.33 per cent of the household aggregated income. The survey asked owners how much they would pay to rent their own house. The average hypothetical rent value was COP\$730,643.6 per month (US\$395.59), 38.54 and 23 per cent of the $\mathrm{HH}$ and all household members' income, respectively.

Neighborhood amenities were obtained at the block level by joining georeferenced cadastral data with the EMB survey information. Cadastral data included mean constructed area, mean cadastral score, an indicator of construction quality ranging from 1 to 100, and Euclidean distances from the housing unit to several attractions. Crime data collected by the National Police for the period 2000-2013 and shared with us under a confidentiality agreement through the Secretary of Government of Bogotá was also included in our data set. We used ESRI geocoder to identify the number of homicides and the number of homes, cars, or persons robbed at the block level where the house belongs. The descriptive statistics of variables used in estimations are available in the online appendix (see tables A1-A3).

\footnotetext{
${ }^{4} \mathrm{~A}$ map with the spatial distribution of the types of dwellings is available in the online appendix.
} 


\subsection{Air quality}

For this empirical exercise, data from Monitoring Stations (Red de Monitoreo de Calidad del Aire de Bogotá - RMCAB) recording PM10 levels for 2011 were gathered to define the air quality variable for estimations of the hedonic pricing model. Using PM10 concentration as the air quality data measure offers two advantages: first, it allows us to work with the city's most relevant pollutant; and second, it is one of the most visible pollutants, helping to mitigate possible biases due to subjective perceptions of pollution. To obtain a measure of air quality for each of the households in our sample of the EMB, we used Voronoi Neighborhood Averaging methodology (VNA) to interpolate monitoring data, mimicking the method used by the EPA's Environmental Benefits Mapping and Analysis Program (RTI International, 2015). In 2011, the mean annual PM10 concentration was obtained from 12 stations of the RMCAB. These data were previously validated by the Monitoring Stations as well as published in RMCAB's webpage. We chose the VNA interpolation over other available techniques because it avoids the interpolation of data at the urban fringe, where there were not enough stations. ${ }^{5}$ The PM10 data as well as the locations of the dwellings in the EMB sample are shown in figure A1 in the online appendix. Even though our study area encompasses a single urban area, we identified some spatial variation in pollution levels: high PM10 concentrations were observed in the south and southwest areas of the city, while the north and central areas presented relatively low measures. Additional measures of air quality were gathered so that we could test for the robustness of the results to different measures of PM10. Particularly, we also calculated air quality data by inverse distance weighted (IDW) interpolation, which is a more standard interpolation technique.

As was mentioned earlier, we also interpolated other pollutant data for overcoming omitted variable bias: Carbon Monoxide (CO), Sulfur Dioxide $\left(\mathrm{SO}_{2}\right)$ and Tropospheric Ozone $\left(\mathrm{O}_{3}\right)$ were included in the estimations. For interpolation methods, we used the mean annual stock of concentrations as the proxy variable for air quality. Basic descriptive statistics are shown in table A3 of the online appendix, as well as their correlation matrix with PM10 measures (table A4). ${ }^{6}$ As it was expected, these variables are highly correlated, either positively or negatively. These correlations are also statistically significant. As we expect, sulphur dioxide and carbon monoxide correlate directly with PM10, considering that there are chemical processes that relate them (Doğruparmak and Özbay, 2011; Sharma and Sharma, 2016).

\section{Empirical results}

\subsection{First stage estimation - the hedonic price function (HPF)}

The HPF in (3) was estimated using a semi-log (log-lin) functional form. Rental prices were used as our housing values. Table 1 presents a summary of the price schedule for Bogotá's dwelling market. ${ }^{7}$ Column (1) presents the results for the entire market,

\footnotetext{
${ }^{5}$ By applying VNA, we effectively used 6061 observations available in the EMB. Because houses do not select their residences based on the position of the RMCAB monitoring stations, we do not believe that this reduction in observations should be biasing our sample. Still, we found that many of our results could be replicated by using other interpolation techniques.

${ }^{6} \mathrm{SO}_{2}, \mathrm{CO}$ and $\mathrm{O}_{3}$ are secondary pollutants in Bogota in 2011, so they were measured in less stations than PM10. To avoid lost of observations we interpolated them by using the IDW technique.

${ }^{7}$ Complete results from estimations are available in the online appendix, table A5.
} 
Table 1. Hedonic Price Function estimation

\begin{tabular}{|c|c|c|c|c|}
\hline & $\begin{array}{c}1 \\
\text { All }\end{array}$ & $\begin{array}{c}2 \\
\text { Apart. }\end{array}$ & $\begin{array}{c}3 \\
\text { Condos }\end{array}$ & $\begin{array}{c}4 \\
\text { House }\end{array}$ \\
\hline PM10 & $\begin{array}{c}-0.015372^{* * *} \\
0\end{array}$ & $\begin{array}{c}-0.0061217^{* *} \\
0\end{array}$ & $\begin{array}{c}-0.024382^{*} \\
-0.01\end{array}$ & $\begin{array}{c}-0.021776^{* * *} \\
-0.01\end{array}$ \\
\hline Structural & Yes & Yes & Yes & Yes \\
\hline Security & Yes & Yes & Yes & Yes \\
\hline Cadastral & Yes & Yes & Yes & Yes \\
\hline Owner bias & Yes & Yes & Yes & Yes \\
\hline Other pollutants & Yes & Yes & Yes & Yes \\
\hline Spatial fix effects & Yes & Yes & Yes & Yes \\
\hline$N \sigma_{\mu}^{2}$ form & $\begin{array}{l}\text { 6,061 PM10, Strata, } \\
\text { Strata*PM10, } \\
\text { Spatial fix eff. }\end{array}$ & $\begin{array}{l}\text { 4,153 PM10, Strata, } \\
\text { Strata*PM10, } \\
\text { Spatial fix eff. }\end{array}$ & $\begin{array}{l}319 \text { PM10, Strata, } \\
\text { Strata*PM10, } \\
\text { Spatial fix eff. }\end{array}$ & $\begin{array}{c}\text { 1,562 PM10, Strata, } \\
\text { Strata*PM10, } \\
\text { Spatial fix eff. }\end{array}$ \\
\hline
\end{tabular}

Standard errors in parentheses.

${ }^{*} p<0.1,{ }^{* *} p<0.05,{ }^{* * *} p<0.01$.

polling all types of properties. Columns (2), (3), and (4) show the submarket estimation results for apartments, condominiums, and houses, respectively. All four models include variables (shown in the online appendix table A5) related to structural dwelling characteristics (Structural), neighborhood characteristic variables related to security (Security), distances to principal amenities (Distance), and structural characteristics of the nearby houses (Cadastral), locality fixed effects, $\mathrm{CO}, \mathrm{SO}_{2}$ and $\mathrm{O}_{3}$ among others. The dependent variable includes both the reported value of rent for renters and hypothetical (imputed) rent value for owners. We intended to capture differences between these two prices by adding a dummy equal to one in case the dwelling is rented as well as its interactions with all the variables. We called this specification an 'owner bias specification'. Finally, the structure for the asymmetrical error variance is specified in the last row, following the specification in equation (4).

Regarding PM10, our variable of interest, results suggest a negative relationship between PM10 concentration and rental prices. The model predicts that an increase of $1 \mu \mathrm{g} / \mathrm{m}^{3}$ is accompanied by a monthly average rent reduction of 0.61 per cent for apartments, of 2.43 per cent for condominiums, and of 2.17 per cent for houses. An increase of $7.71 \mu \mathrm{g} / \mathrm{m}^{3}$ (the standard deviation of the PM10 concentration by household) reduces rent prices by 4.7 per cent in the first submarket, 18.73 per cent in the second submarket, and 16.73 per cent in the third one $(1.62,6.93$, and 8.63 per cent of $\mathrm{HH}$ monthly income, respectively).

Coefficient results for other variables (shown in the online appendix) had the expected signs. The number of rooms (numCuartos) has a positive effect on the rents, increasing them from 2.97 to 6.98 per cent for each additional room. An increase in one bathroom (banios) increased rent from 12.29 to 16.23 per cent. The model also shows that an increase in one case of homicide in the block is associated with a decrease in the rent from 0.67 to $9.95 \mathrm{p}$ per cent. Neighborhood quality, measured by the cadastral score for the census track where the residence is located, also has a positive effect on price, as was expected. 


\subsection{Second stage estimation - demand for reductions of air pollution}

Based on the predicted effect of the PM10 concentration on property rents, the implicit price for the reduction of air pollution $\left(W\left(P M 10_{\mathrm{ij}}\right)\right)$ is calculated. Because defining apartment, condominium, and house submarkets already solves the SS identification issue by estimating information for multiple markets, the only problem that is still unresolved is the endogeneity issue.

A 2SLS method is used to obtain consistent estimations of the demand parameters under a linear specification. Optimum instrumental variables could be defined based on those variables that affect PM10 concentrations, but not house prices. The selected instruments are rainfall, wind speed and a PM10 spatial lag. At a large geographical scale, rainfall would likely have a direct effect on property values, as Albouy et al. (2016) found in the U.S for climate valuation. However, at an intra-urban scale, we argue that rainfall is a suitable instrument since variation in rain patterns among neighborhoods is not likely to influence property values within a city. Nonetheless, rain directly influences pollution levels by washing the atmosphere, even at a small spatial scale. Also, there is no reason to expect any direct effect on wind speed on dwellings' prices in Bogotá. Still, previous works have identified a strong relationship between wind speed and the concentration of several pollutants (Verma and Desai, 2008), including PM10 (Tian et al., 2008). Tian et al. (2008) identify this relationship as not linear so our instruments also include the quadratic and cubic form of this variable. Finally, following Anselin and Lozano-Gracia (2008) design, we included a PM10 spatial lag as an instrument. Table 2 shows a summary of the first stage results of the 2SLS in column (1) and the second stage in column (2), correcting again by clusters in the estimation. ${ }^{8}$ As was expected, more rain is associated with less concentration of PM10, wind speed presents a non-linear relation with PM10 and the spatial lag (WPM10) is highly significant. The Hausman test, an instruments relevance test, and Hansen's J statistic for over-identification are also reported in table 2. All three tests suggest that the model is well specified.

The second column also shows expected results in the estimation of the linear demand for reduction in air pollution. The results show that air pollution reduction is a normal good, meaning that it is affected positively by income. Other socio-demographic variables are reported in table A6 in the online appendix. Head of Household's (HH) age and education have a positive effect on the willingness to pay for pollution reductions. We also found that some characteristics of the dwellings are substitutes of air quality, including number of bedrooms (numCuartos) and neighborhood quality (Puntaje).

Finally, the SS hedonic estimation shows that the demand for air quality satisfies the law of demand. In a low-middle income city like Bogotá, we expect a high response of air quality to implicit price changes. At the mean, the demand for air quality will decrease by 1.39 per cent with an increase of 1 per cent in price. Although this elasticity seems relatively high $(-1.39)$, our estimated elasticity lies in the range of previously estimated elasticities using SS of the hedonic models for air quality. Brasington and Hite (2005) and Zabel and Kiel (2000) find more inelastic demand functions, -0.12 and -0.219 respectively, while Chattopadhyay (1999) found a more elastic demand (-2.04)

\subsection{Welfare measures}

Welfare measures for non-localized amenities like air quality or any housing characteristic whose changes affect all agents in the market should be calculated based on the

\footnotetext{
${ }^{8}$ Complete results are available in the online appendix. Please see table A6.
} 
Table 2. Demand for air quality estimation

\begin{tabular}{|c|c|c|}
\hline & $\begin{array}{c}\text { (1) } \\
\text { First stage }\end{array}$ & $\begin{array}{c}(2) \\
\text { Second stage }\end{array}$ \\
\hline \multirow[t]{2}{*}{ PM10 } & & $-0.057522^{* * *}$ \\
\hline & & -0.01 \\
\hline \multirow[t]{2}{*}{ Rainfall } & $-0.0057113^{* *}$ & \\
\hline & 0 & \\
\hline \multirow[t]{2}{*}{ Wind speed } & $19.996^{* * *}$ & \\
\hline & -5.92 & \\
\hline \multirow[t]{2}{*}{ Wind speed ${ }^{2}$} & $-9.3602^{* * *}$ & \\
\hline & -3.17 & \\
\hline \multirow[t]{2}{*}{ Wind speed ${ }^{3}$} & $1.4206^{* * *}$ & \\
\hline & -0.54 & \\
\hline \multirow[t]{2}{*}{ WPM10 } & $1.0011^{* * *}$ & \\
\hline & -0.02 & \\
\hline \multirow[t]{2}{*}{ Ingresos } & $-5.03 \times 10^{-06}$ & $0.0001853^{* * *}$ \\
\hline & 0 & 0 \\
\hline$R^{2}$ & & 0.28 \\
\hline$N$ & 5,694 & 5,694 \\
\hline Other socio-demographical variables & \multicolumn{2}{|c|}{$\begin{array}{l}\text { Educations, } \mathrm{HH} \text { sex, } \mathrm{HH} \text { age, } \mathrm{HH} \text { number of kids, } \\
\text { partipating in env. organizations, other dwelling } \\
\text { characteristics }\end{array}$} \\
\hline Hausman pValor & & 0.01 \\
\hline Relevance pValor & & 0 \\
\hline Hansen pValor & & 0.73 \\
\hline Var. Est. & Robust cluster & Robust cluster \\
\hline
\end{tabular}

Standard errors in parentheses.

${ }^{* *} p<0.05,{ }^{* * *} p<0.01$.

demand from the SS and not from the FS hedonic estimation (Taylor, 2003). The area under the derived demands will show the total willingness to pay for a certain reduction of PM10.

Figure 2 shows the demand curves estimated in table 2. The shaded areas of the graph show the total monthly willingness to pay per household for air quality that satisfies both the WHO standard (left) and the national standard (right) given an initial level of pollution of $51.78 \mu \mathrm{g} / \mathrm{m}^{3}$. A reduction in air pollution of PM10 up to $50 \mu \mathrm{g} / \mathrm{m}^{3}$ will equate with a total willingness to pay of US\$12.16 per month per household, or 1.35 per cent of monthly income. The total willingness to pay for a PM10 reduction up to $20 \mu \mathrm{g} / \mathrm{m}^{3}$ amounts to US\$189.64 per month per household, which represents 21.04 per cent of monthly income. Table 3 presents these results and disaggregates the effects by low, medium, and high socioeconomic strata. 
Demand for Air Quality

Welfare derived from PM10 pollution reductions to $20 \mu \mathrm{g} / \mathrm{m}^{3}$ and $50 \mu \mathrm{g} / \mathrm{m}^{3}$
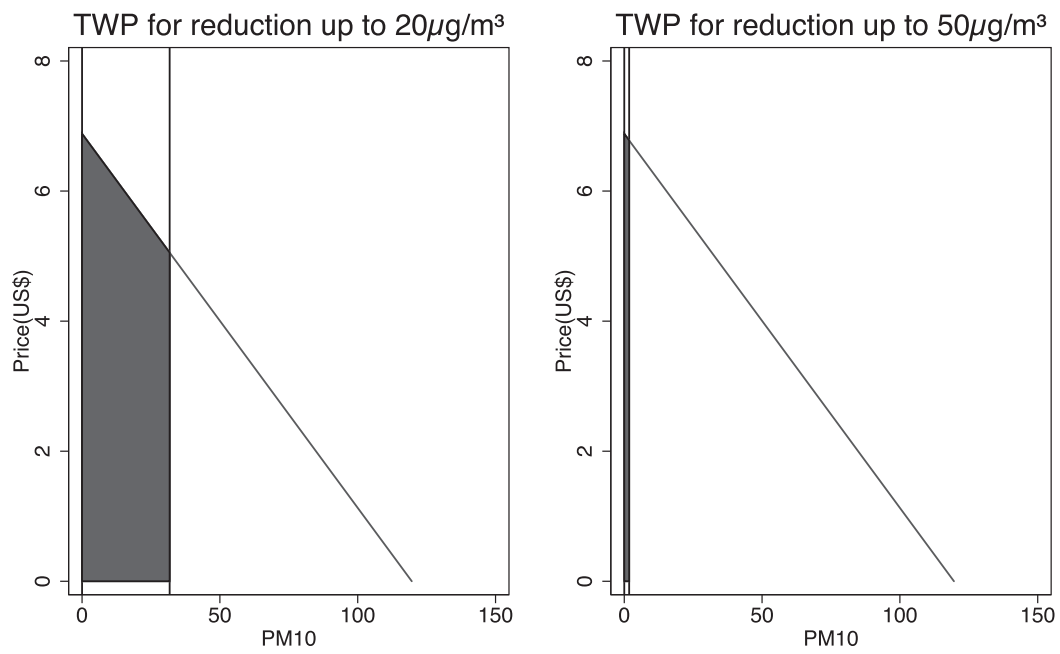

Figure 2. Demand for Air Quality

Table 3. Welfare measures

\begin{tabular}{lccccc}
\hline & Elasticity (\%) & \multicolumn{2}{c}{ TWP for $20 \mu \mathrm{m} / \mathrm{m}^{3}$} & \multicolumn{2}{c}{ TWP for $50 \mu \mathrm{m} / \mathrm{m}^{3}$} \\
\hline General & -1.31 & 189.64 & $(21.04)$ & 12.16 & $(1.35)$ \\
\hline Low Strata & -0.82 & 152.42 & $(37.47)$ & 10.07 & $(2.48)$ \\
\hline Med Strata & -1.52 & 211.41 & $(19.88)$ & 13.38 & $(1.26)$ \\
\hline High Strata & -2.88 & 263.69 & $(8.12)$ & 16.31 & $(0.5)$ \\
\hline
\end{tabular}

Percentage of monthly income in square brackets.

We carried out several robustness checks: first, we tested the suitability of the proposed market segmentation by applying a Chow Test and a Two Step Clustering Method. Second, we tested different functional forms of the hedonic function as well as different air quality measures. Third, we compared OLS estimations of the FS hedonic model with the Frontier Model Specification. Finally, we checked the robustness of the demand function for air quality to different instruments. Complete results of robustness checks are discussed in the online appendix (please see tables RC1 and RC2 in the online appendix).

\section{Discussion}

Results from the FS hedonic model confirm that air quality is capitalized into property values in Bogotá. However, such capitalization varies from one housing submarket to another. A Chow test concludes in favor of separate housing submarkets and, therefore, this test suggests a non-unique HPF for Bogotá.

The proposed market segmentation within the city helped us estimate a SS hedonic model to identify a demand for air quality while relying on information obtained from 
the market process. This market segmentation could be defined by non-market valuation practitioners interested in applying the SS hedonic model within any urban area where apartments, houses and condominiums are the most prevalent types of residential housing.

We address identification and endogeneity issues by using housing submarkets and an IV econometric strategy. Results of the SS confirm the demand law and the hypothesis that air quality is a normal good. An identification of a demand function for air quality is a suitable and very flexible tool for policy makers interested in identifying non-marginal benefits (costs) from air quality improvements (deterioration). We illustrated the flexibility with which the demand function could be used to calculate benefits for various ambient quality scenarios: benefits from compliance to the EPA standard amount to US $\$ 12.16 /$ month/household, whereas compliance with the more stringent WHO standard brings benefits close to US $\$ 189.64 /$ month/household. The latter may seem high in magnitude for a city like Bogotá. Nonetheless, these estimates correspond to nonmarginal changes of pollution levels calculated from the area below a demand curve (Total Willingness to Pay.) These estimates do not entail the usually reported marginal implicit price from FS hedonic applications. Furthermore, the non-marginal changes correspond to a reduction of more than 50 per cent of the average PM10 pollution levels. Nonetheless, our estimated values from revealed preferences could be incorporated in a cost/benefit analysis for regulatory policies to control urban air pollution.

\section{Supplementary material}

The supplementary material for this article can be found at https://doi.org/10.1017/ S1355770X18000050.

\section{References}

Albouy D, Graf W, Kellog R and Wolff H (2016) Climate amenities, climate change, and American quality of life. Journal of the Association of Environmental and Resource Economists 3(1), 205-45.

Anselin L and Le Gallo J (2006) Interpolation of air quality measures in hedonic house price models: spatial aspects. Spatial Economic Analysis 1(1), 31-52.

Anselin L and Lozano-Gracia N (2008) Errors in variables and spatial effects in hedonic house price models of ambient air quality. Empirical Economics 34(1), 5-34.

Bartik TJ (1987) The estimation of demand parameters in hedonic price models. The Journal of Political Economy 95(1), 81-88.

Bayer P, Keohane N and Timmins C (2006) Migration and hedonic valuation: the case of air quality. Journal of Environmental Economics and Management 58(1), 1-14.

Boyle MA and Kiel KA (2001) A survey of house price hedonic studies of the impact of environmental externalities. Journal of Real Estate Literature 9(2), 117-144.

Boyle KJ, Poor PJ and Taylor LO (1999) Estimating the demand for protecting freshwater lakes eutrophication. American Journal of Agricultural Economics 81(5), 1118-1122.

Brasington DM and Hite D (2005) Demand for environmental quality: a spatial hedonic analysis. Regional Science and Urban Economics 35(1), 57-82.

Carriazo F, Ready R and Shortle J (2013) Using frontier stochastic models to mitigate omitted variable bias in hedonic pricing model: a case study for air quality in Bogotá, Colombia. Ecological Economics 91, 80-88.

Chattopadhyay S (1999) Estimating the demand for air quality: new evidence based on the Chicago housing market. Land Economics 75(1), 22-38.

Chay KY and Greenstone M (2005) Does air quality matter? Evidence form the housing market. Journal of Political Economy 113(2), 376-424.

Cheshire P and Sheppard S (1998) Estimating the demand for housing, land, and neighbourhood characteristics. Oxford Bulletin of Economics and Statistics 60(3), 357-382. 
Departamento Administrativo Nacional de Estadística - DANE (2016) Índice de Costos de la Construcción de Vivienda - ICCV. Available at http://www.dane.gov.co/index.php/estadisticas-por-tema/ construccion/indice-de-costos-de-la-construccion-de-la-vivienda/iccv

Departamento Administrativo Nacional de Estadística - DANE (2017) Censo de Edificaciones CEED. Available at http://www.dane.gov.co/index.php/estadisticas-por-tema/construccion/censo-deedificaciones.

Doğruparmak ŞÇ and Özbay B (2011) Investigating correlations and variations of air pollutant concentrations under conditions of rapid industrialization-Kocaeli (1987-2009). CLEAN-Soil, Air, Water 39(7), 597-604.

Freeman M (1979) Hedonic prices, property values and measuring environmental benefits: a survey of the issues. The Scandinavian Journal of Economics 81(2), 154-173.

Freeman M (2003) The Measurement of Environmental and Resource Values: Theory and Methods, 2nd edn., Washington, DC: Resources for the Future.

Gaitán M, Cancino J and Behrentz E (2007) Análisis del estado de calidad del aire en Bogotá. Revista de Ingeniería 26, 81-92.

Goodman AC and Thibodeau TG (2003) Housing market segmentation and hedonic prediction accuracy. Journal of Housing Economics 12(3), 181-201.

Harrison D and Rubinfeld DL (1978) Hedonic housing prices and the demand for clean air. Journal of Environmental Economics and Management 5(1), 81-102.

Kim CW, Phipps TT and Anselin L (2003) Measuring the benefits of air quality improvement: a spatial hedonic approach. Journal of Environmental Economics and Management 45(1), 24-39.

Kuminoff NV, Parmeter CF and Pope JC (2010) Which hedonic models can we trust to recover the marginal willingness to pay for environmental amenities? Journal of Environmental Economics and Management 60(3), 145-160.

Mínguez R, Montero JM and Fernández-Avilés G (2013) Measuring the impact of pollution on property prices in Madrid: objective versus subjective pollution indicators in spatial models. Journal of Geographic Systems 15(2), 169-191.

Morales ZL and Arias Arbeláez FA (2005) La Calidad de la Vivienda en Bogotá: Enfoque de Precios Hedónicos Y de Agregados Espaciales. Revista, Sociedad y Economía, (9), 47-80.

Neill HR, Hassenzahl DM and Assane DD (2007) Estimating the effect of air quality: spatial versus traditional hedonic price models. Southern Economic Journal 73(4), 1088-1111.

Palmquist RB (1984) Estimating the demand for air quality from property value studies: further results. U.S. Environmental Protection Agency, Economic Analysis Branch, Office of Air Quality Planning and Standards.

Palmquist RB (2005) Property value models. In Mäler KG and Vincent J (eds). Handbook of Environmental Economics: Valuing Environmental Changes, (vol. 2). Elsevier, pp. 763-819.

Ridker RG and Henning JA (1967) The determinants of residential property values with special reference to air pollution. Review of Economics and Statistics 49, 246-25.

Rosen S (1974) Hedonic prices and implicit markets: product differentiation in pure competition. The Journal of Political Economy 82(1), 34-55.

RTI International (2015) Environmental Benefits Mapping and Analysis Program - Community Edition. User's Manual. Available at http://www2.epa.gov/sites/production/files/201504/documents/benmapce_ user_manual_march_2015.pdf

Sharma RC and Sharma N (2016) Influence of some meteorological variables on PM10 and NOx in Gurgaon, Northern India. American Journal of Environmental Protection 4(1), 1-6.

Secretaria Distrital de Ambiente - SDA (2011) Documento técnico -línea de Intervención aire, ruido y radiación electromagnética. Bogotá.

Smith VK and Huang JC (1993) Hedonic models and air pollution: twenty-five years and counting. Environmental and Resource Economics 3(4), 381-394.

Smith VK and Huang JC (1995) Can markets value air quality? A meta-analysis of hedonic property value models. Journal of Political Economy 103(1), 209-227.

Superintendencia de Industria y Comercio - SIC (2012) Estudio sobre el sector vivienda en Colombia. Estudios de Mercado 4. Available at http://www.sic.gov.co/recursos_user/documentos/promocion_ competencia/Estudios_Economicos/Estudios_Economicos/Estudios_Mercado/estudioSectorial Vivienda.pdf 
Taylor LO (2003) The hedonic method. In Champ P, Boyle K and Brown T (eds). A Primer on Nonmarket Valuation. Dordrecht: Springer, pp. 331-393.

Tian G, Fan SB, Huang YH, Nie L and Li G (2008) Relationship between wind velocity and PM10 concentration and emission flux of fugitive dust source. Huan Jing Ke Xue 29(10), 2983-2986.

Vásquez LF, Dresdner J and Aguilar R (2011) The value of air quality and crime in Chile: a hedonic wage approach. Environment and Development Economics 16, 329-355.

Verma SS and Desai B (2008) Effect of meteorological conditions on air pollution of Surat city. J. Int. Environmental Application and Science 3(5), 358-367.

Zabel J and Kiel K (2000) Estimating the demand for air quality in four U.S. cities. Land Economics 76(2), 174-194.

Cite this article: Carriazo F, Gomez JA (2018). The demand for air quality: evidence from the housing market in Bogotá, Colombia. Environment and Development Economics 23, 121-138. https://doi.org/10. 1017/S1355770X18000050 